\title{
El general en su laberinto de Gabriel García Márquez. Visión posmoderna de la historia latinoamericana
}

\author{
Héctor Azzetti \\ Esta época ha visto desaparecer el gran héroe, los grandes peligros, los \\ grandes periplos y el gran fin. Se acabaron los metarrelatos. J.F.Lyotard
}

Marx y Freud son quizd́s el alba de nuestra cultura, pero Nietzsche es totalmente otra cosa. El alba de una contracultura. G.Deleuze

Creemos que las frases de los epigrafes podrían sintetizar con justeza nuestra percepción de la Modernidad, a la que entendemos como el fenómeno filosófico-cultural desarrollado a partir de las últimas décadas del siglo $\mathrm{XX}$, en la que incluimos a la llamada Posmodernidad como último segmento, caracterizada a grandes rasgos por una alteración de la tranquilidady el orden emergentes de las certezas de las ideologías.

Tan amplio e intrincado fenómeno nos obliga a un planteo sintetizador y esquemático a través de la mención y breve justificación de las coordenadas que, desde nuestra perspectiva, aparecen como funcionales al abordaje de una lectura de la literatura latinoamericana de fines del siglo XX, preocupada por desentraffar ciertos núcleos problemáticos de su dimensión histórica.

A modo de metáfora totalizadora adjudicamos a tres episodios históricos la responsabilidad de haber iniciado el socavamiento de la tranquilidad y de las certezas ideológicas, inherente a las revoluciones modernas, rẹalizado con materiales diversos y complejos, hasta entonces inéditos en este tipo de avatares históricos. Nos referimos a: la revolución cultural china (agosto de 1966); la revolución del mayo francés (1968) y al desastre de Chernobyl (abril de 1986). Aceptamos que estos tres episodios dibujan un mapa más bien escueto, caprichoso y hasta paradójico, pero para defender su presencia en este trabajo, en primer lugar nos amparamos en la lectura de la Modernidad realizada por los autores de los epigrafes, que seguimos en líneas generales, y en segundo lugar asumimos la convicción de que esta secuencia nos muestra la eclosión sucesiva de tres gérmenes ideológicos que harán metástasis en el cuerpo social, universalizarán una forma hasta esos momentos inédita de revolución y replantearán las verdades históricas a través de la perspectiva de un relativismo oscilante entre la negación y el nihilismo.

Desde la dimensión del contenido y la significación, cada uno de estos acontecimientos, que en el proceso histórico son a su vez causas y efectos de fisiones en cadena, impondrán sucesivamente el politicismo (relativismo marxista nacido de sus propias entrafias), el estructuralismo y la interdisciplinariedad, y la crisis de la cientificidad, especies de ejes conceptuales que podrían explicar la Modernidad desde el ángulo de lectura que elegimos. Por ello, los tres nombres que colocaremos en los vértices de este triángulo son: Marx, Nietzsche y Freud, porque en nuestra línea de abordaje generan y orientan todo lo que pasa en la Modernidad. La Linguística, el Psicoanálisis, la Socioeconomía, constituyen vias de acceso que nos llevan a los distintos laberintos y vericuetos que resquebrajan y anulan los 
sistemas constituidos, sobrevivientes de las vanguardias. Las intersecciones múltiples de estas líneas primero hacen languidecer y luego quiebran al ya anacrónico Hegel y con las migajas resultantes construyen los puzzles de los nuevos sistemas.

Sin embargo, la Modernidad, vista desde este ángulo de mira, carece de la espectacularidad de las impugnaciones explosivas, en virtud de que las grandes dimensiones no desaparecen como horizontes epistemológicos. La Historia, lo Social, la Ideología, el Individuo permanecen incólumes aunque cambian los modos de acceso a sus esencias, en virtud de que ya no se los administra desde Arriba, desde los Universales, sino desde los Singulares, es decir, ya no se sustentan en las grandes consignas y en los dogmas espectaculares. La verdad deja lugar a la Verosimilitud y a la Rigurosidad. Las tensiones entre fuerzas y contrafuerzas provocan la carnavalización del pensamiento y generan la paradoja de una contracultura institucionalizada. En el tramo de la Posmodernidad, el intelectual es eyectado a un mar turbulento: flota entre muchas teorias y discursos, se debate en un eclecticismo de síntesis, de ambigledad de la certeza. Paralelamente, las utoplas se desarman, o peor aún, envilecen sus propósitos y metas fundacionales.

Tanto los acontecimientos históricos como los hombres que hemos considerado paradigmáticos de la Modernidad son intercambiables, dada su condición alegórica y metaforizante en relación con determinadas perspectivas y enfoques. En efecto, desde una visión habermasiana, en la filosofia del siglo $\mathrm{XX}$ se destacan cuatro complejos bien diferenciados: la filosofia analítica, la fenomenología, el marxismo occidental y el estructuralismo, que en su carácter de "figuras del espiritu" al decir de Hegel están condenadas a perecer, previo pasaje por los respectivos "post". Afirma Habermas que "lo especificamente moderno, que se ha apoderado de todos los movimientos de pensamiento, radica no tanto en el método como en los motivos de ese mismo pensamiento". Es decir, la ruptura con la tradición se caracteriza por cuatro motivos cuyos rótulos son los siguientes: "pensamiento postmetafísico, giro linguístico, carácter situado de la razón e inversión del primado de la teoría sobre la praxis - superación del logocentrismo"'. Estos motivos, según Habermas, corresponden a los impulsos más importantes del pensamiento del siglo $\mathrm{XX}$, y aunque han conducido a nuevas verdades, también han producido nuevas limitaciones.

\section{La reescritura de la historia en la Narrativa Hispanoamericana}

Desde la década del 70 del siglo pasado asistimos en Hispanoamérica a un verdadero boom de la novela histórica, cuya estructura compositiva difiere significativamente de sus precedentes románticos y realistas. En efecto, el verdadero aluvión que generó esta forma novelesca en los últimos tiempos, en virtud de disefiar perspectivas múltiples y diferentes a las versiones historiográficas en relación con hechos y personajes de nuestra historia, ha sido calificado por la mayoría de los críticos como Nueva novela histórica o reescritura ficcional de la historia. (Menton)

Inserto plenamente en la Modernidad, la reescritura ficcional de la historia configura un fenómeno complejo de la literatura hispanoamericana, surgido de la necesidad de desmitificar el pasado y multiplicar los puntos de vista, en un intento por impedir el acceso a una sola verdad histórica. Es coherente con el relativismo, la desconstrucción y la degradación de los mitos nacionales propios de la modernidad, asumidos en la escritura como un 
contradiscurso impugnador o al menos cuestionador del discurso historiografico oficial. Por ello, las modalidades dominantes son la parodia y la ironía, la superposición de los tiempos y la diversidad de formas expresivas, en las cuales se encierra una actitud autocrítica y de negación al superponerse a los episodios históricos y a los personajes verdaderos de la historia, con el fin de desplazarlos y resignificarlos. En efecto, no se trata ya de incluir, con mayor o menor felicidad, en la trama de los hechos y los personajes a lo real histórico, sino, tal como lo afirma Janina Montero, abordar un "planteamiento histórico antioficial", desarrollar una "contrahistoria que intente desenmascarar el triunfalismo de las formas autorizadas".

En Hispanoamérica sobreviven tensiones históricas no resueltas desde el mismo descubrimiento, alimentadas por posiciones encontradas, por versiones divergentes no solo de los hechos históricos sino respecto de la actuación de sus protagonistas. Un trasfondo ambiguo y polémico recorre toda nuestra historia, promoviendo la proliferación de lecturas diversas propiciadas por el propio discurso histórico. Este fondo polémico connatural a la historia de Hispanoamérica, genera replanteos, enjuiciamientos, algunos de ellos muy severos, versiones cuestionadoras de la que podría sostenerse como "historia oficial", en este caso desde una novelistica que asume también su escritura como una reescritura crítica de la historia. Hechos puntuales, fenómenos históricos de dimensión nacional o continental, personajes próceres y figuras secundarias, son objeto de revisión por parte de esta narrativa que desde la literatura aventura visiones alternativas de la "verdad historica", solapadas en los pliegues siempre ambiguos, generalmente irónicos y alegóricos, de la ficción novelesca.

Fijar fronteras y límites en un continuum tan complejo y dinámico como la literatura latinoamericana, constituye un esfuerzo dificultoso y en cierto sentido inoperante. No obstante, por una necesidad de sistematización, consideramos en estos comentarios a la década del $\mathbf{7 0}$ como una especie de bisagra que proyecta la efervescencia del llamado boom de los 60 hacia derivaciones que algunos criticos denominaron sencillamente el postboom, entre cuyas vertientes rescatamos a la llamada Nueva novela histórica latinoamericana, objeto de nuestras reflexiones en esta circunstancia.

Sólo por mencionar las más significativas de un catálogo profuso y heterogéneo, consignamos como las primeras manifestaciones de esta corriente a novelas como Yo, el Supremo (1974) del paraguayo Augusto Roa Bastos y Terra Nostra (1975) del mexicano Carlos Fuentes, a las que siguen en la misma década Daimon (1978) de Abel Posse (Argentina) y $E l$ arpa y la sombra (1979) de Alejo Carpentier (Cuba). La década siguiente se inicia con dos obras paradigmáticas de la reescritura histórica de la contemporaneidad, en virtud de la incorporación en sus respectivas estructuras compositivas de estrategias y artificios experimentales, fenómenos que en obras posteriores de esos mismos autores disminuyen su presencia ante la recuperación de un discurso narrativo menos artificioso y más comprometido con la secuencia de los hechos narrados. Nos referimos a Respiración Artificial de Ricardo Piglia (Argentina, 1980) y La guerra del fin del mundo de Mario Vargas Llosa (Perú, 1981).

Mencionamos seguidamente, a manera de enumeración sumaria, algunas obras que estimamos significativas de la Nueva Novela histórica latinoamericana, aparecidas desde los años 80 en adelante: Los perros del paraíso de Abel Posse (Argentina, 1983), El Entenado de Juan José Saer (Argentina, 1983), Gringo viejo de Carlos Fuentes (México, 1985), La revolución es un sueño eterno de Andrés Rivera (Argentina, 1987), Memorias del nuevo mundo de Homero Aridjis (México, 1988), El general en su laberinto de Gabriel García Márquez (Colombia, 1989), La gesta del marrano de Marcos Aguinis (Argentina, 1991), La 
visita del tiempo de Arturo Uslar Pietro (Venezuela, 1990), Vigilia del almirante de Augusto Roa Bastos (Paraguay, 1992), El largo atardecer del caminante de Abel Posse (Argentina, 1992).

\section{Breve caracterización de la Nueva Novela Histórica Latinoamericana}

La caracterización de la novela histórica en general, y de la latinoamericana en particular, reclama el análisis de aspectos muy amplios y profundos que la brevedad de este artículo no nos permite desarrollar en esta ocasión. Por ello, sólo haremos un raudo recorrido por los conceptos de algunos teóricos más reconocidos del género.

Fernando Ainsa ${ }^{1}$ reconoce diez rasgos determinantes de la vertiente narrativa que denomina subgénero de la Novela Histórica contemporánea hispanoamericana, entre los cuales resaltamos: el cuestionamiento al discurso historiográfico oficial; la abolición de la distancia épica, de la historia como disciplina y de la novela histórica tradicional; la degradación de los mitos constitutivos de la nacional a través de la utilización de arcaísmos, pastiches y parodias; la superposición de tiempos diferentes y la multiplicidad de puntos de vista que postulan diversas "verdades históricas" concurrentes; y la diversidad de formas expresivas, entre otros caracteres menos relevantes.

Por su parte, Noé Jitrik ${ }^{1}$ reflexiona sobre el oxímoron que representa la imagen creada por el sintagma "novela histórica". En la tradición occidental, novela remite al orden de la invención, mientras que historia al orden de los hechos. Sin embargo, aclara Jitrik, la expresión es una imagen construida, un producto histórico que tiene su propia historia y está dotada por lo tanto de una autorización filosófica que reduce, y aún anula, la oposición semántica de sus elementos. Para este autor la novela histórica es ficción y en consecuencia sus procedimientos y productos no se hallan sometidos a las modulaciones ni a las condiciones históricas, sino que conllevan la finalidad de dar una forma más precisa a la verosimilitud. Como en toda novela, en la novela histórica el autor "inventa" y "ficcionaliza", estableciendo una relación de jerarquía entre los cuatro términos que operan como cualidades organizativas y compositivas del relato: inteligencia, imaginación, invención, ficción. En consecuencia, para Jitrik la novela histórica es "ficción", entendida ésta como "un particular conjunto de procedimientos determinados y precisos para resolver un problema de necesidad estética"." Asimismo, considera que el recurso al pasado está impuesto por una necesidad de comprender mejor el presente. Dice textualmente Jitrik que "[...] asi como el Romanticismo se vuelca al pasado para paliar su angustia por el presente, la novela histórica intenta, mediante respuestas que busca en el pasado, esclarecer el enigma del presente"l

Seymour Menton' comienza identificándose con la definición, muy clara y simple, de Anderson Imbert que data de 1951: "Llamamos 'novelas históricas' a las que cuentan una acción ocurrida en una época anterior a la del novelista". Luego, en base a su concepción de Nueva Novela Histórica, especifica seis rasgos caracterizadores de esta corriente, los que enunciamos seguidamente en forma sintetizada:

1. La aplicación de ciertas ideas filosóficas de Borges como la imposibilidad de conocer la verdad histórica y el carácter cíclico e imprevisible de la historia, a la reproducción mimética de ciertos períodos y personajes históricos. 
2. La distorsión consciente de la historia mediante omisiones, exageraciones y anacronismos.

3. La ficcionalización de personajes ficticios y personajes destacados de la historia.

4. La metaficción e intervención del narrador o comentador en el proceso de la creación.

5. La intertextualidad, el palimpsesto y la reescritura de otro texto, a través de diversas modalidades que van de la cita apócrifa a la parodia y a las alusiones burlescas y descalificantes.

6. La proyección de dos o más intepretaciones de los sucesos a través de lo dialógico, lo carnavalesco, la parodia y la heteroglosia. Entiende que la incidencia de los estudios de Bajtin es determinante en la proliferación de este rasgo.

Por nuestra parte, queremos señalar que toda novela histórica participa del fenómeno literario y por lo tanto su dimensión factual más notoria y significativa lo constituye la escritura, configurada como el producto de la intención del autor, deliberada y sobreentendida, de poner en acto la voluntad de acción en relación con ciertos sucesos históricos y con la literatura.

En ese sentido, considerado en su nivel de discurso, el referente de la novela histórica es otro discurso, especificamente el de la historia, al que el autor acude a traves de sus conocimientos escolares, de la historiografia, y de la documentación pertinente a los hechos o personajes que configuran el soporte de su obra. Por lo tanto, y dada la necesaria mediación de la interpretación operada sobre ese discurso primario, el referido, al que entendemos como lo construido sobre el material emergente de la interpretación, se halla conformado en el discurso novelesco con los mecanismos de representación que surgen de la relación simbólica con las cosas, los sucesos y los personajes del referente.

La novela histórica no pretende representar el discurso referido sino darle un sentido a ese discurso, es decir, potenciar una finalidad especifica, construir una imagen o representamen que será objeto de interpretación o lectura por parte del lector.

La Nueva Novela Histórica Latinoamericana privilegia el protagonismo de las figuras principales de la historia. Colón, Cortés, Bolivar, San Martín, Rodriguez de Francia, Urquiza, Rosas, Perón, asumen el carácter de personajes de muchas novelas y se erigen en figuras emblemáticas de un referente contextual generalmente critico, cuya lectura ficcional se halla cargada de censura y cuestionamiento. Consolidada en el Romanticismo, la prolongación contemporánea de la novela histórica recupera el pasado a partir de la fuerza centrffuga del hombre representativo saintsimoniano derivado a su vez de la teoria del grande hombre de Hegel y de las preocupaciones románticas por el genio maniqueo del bien y del mal.

En la literatura argentina contemporánea (desde los 80), y creo que el juicio es extensible a toda Latinoamérica, el renacimiento de la novela histórica implica sin lugar a dudas una reescritura de la historia a partir de enfoques y perspectivas generalmente diferentes a las consagradas por la historiografia oficial. En ese sentido, esta corriente literaria, independientemente de la calidad estética de sus productos, bien podría considerarse incorporada a la voluntad revisionista de la historia, cuyos fundamentos y estrategias pasan por la riqueza interpretativa propuesta por la ficcionalización de los suefros y de los personajes. Conforme a la visión sintética de estas reflexiones, la Nueva Novela Histórica Latinoamericana parece decirnos por una parte que la historia no es sólo problema de la historiografia, y por otra que no existe una historia verdadera, más aún que las verdades históricas son diversas y 
múltiples, como lo son los puntos de mira de quien se asoma a observarlas, sea éste novelista o historiador, 0 ambas cosas a la vez.

\section{El General en su laberinto}

El general en su laberinto constituye uno de los ejemplos más claros, y además patético, de la reescritura de la historia por parte de la novela latinoamericana. Más que reescribirla, dibuja una sobreescritura al margen de la historiografia oficial ya que cambia la iconografia del prócer, sustituyendo la actitud gloriosa y triunfal del mármol por la figura del Bolivar muriente, con su cuerpo estragado y disminuido que no termina de morir porque sigue vivo en las tensiones irresueltas del suefío bolivariano de la Gran Colombia.

"José Palacios, su servidor más antiguo, lo encontró flotando en las aguas depurativas de la bañera, desnudo y con los ojos abiertos, y creyó que se habia ahogado." En la frase inicial de la novela ya se postulan los vectores con que la escritura novelesca traspondrá a clave simbólica la historicidad de los hechos para convertirlos en secuencias de una trama patética: el realismo mágico de la imagen, la inminencia de la muerte y el flotar del cuerpo ingrávido del general.

Los ocho capitulos sin numerar de la novela seffalan otras tantas estaciones de la travesia de Bolívar por el rio Magdalena durante sus últimos siete meses de vida. Configura un itinerario que asume la simbología de un via crucis por el suef́o ya muerto de la unidad latinoamericana, una persecución sin sentido signada de antemano por la frustración y el fracaso. "En suma, concluyó el general, todo lo que hemos hecho con las manos lo están desbaratando los otros con los pies" (126), afirma antes de partir con la desazón del derrotado después "de veinte años de guerras inútiles y desengaños de poder" (13). La novela se revela entonces como una versión de la última aventura del personaje en el balance de su utopla, que debe ser leída por la actualidad como el fracaso de la concepción unitaria de América Latina, causa a su vez de sus males crónicos y de sus crisis eternas. Ante la enemistad con Santander, desencadenante de la definitiva escisión de Venezuela, Bolívar afirma en la novela que "la verdadera causa fue que Santander no pudo asimilar nunca la idea de que este continente fuera un solo pais, para agregar a renglón seguido que la unidad de América le quedaba grande". (125)

El itinerario por el Magdalena, al carecer de una expectativa promisoria, constituye un viaje sin fin hacia ninguna parte. Al promediar la travesía, los militares subalternos que lo acompañan están tan seguros como él de la inutilidad del intento:

lo que no podían soportar era la incertidumbre que él les había ido infundiendo desde que tomó la decisión de abandonar el poder, y que se hacía más y más insoportable a medida que seguía y se empantanaba aquel viaje sin fin hacia ninguna parte. (171)

El general Carreño, uno de sus acompañantes, había decidido escapar a Venezuela, su patria, para organizar desde alli un movimiento armado en pro de la restauración de la ciudad. Sin embargo, el mismo Bolivar, en pleno periplo cuya finalidad primordial era el rescate del suefio unitario, increpa a su subordinado: "no seas pendejo,...para nosotros la patria es 


\begin{abstract}
América, y toda está igual: sin remedio para rematar con un dramático no delires más, Carreño... esto se lo llevó el carajo." (172)

Siguiendo los conceptos teóricos desgranados en la introducción, podemos afirmar que la reescritura en clave simbólica de la novela reconoce como referente la frustración de la unidad soffada por Bolivar, y como referido, el proceso de decadencia y la toma de conciencia del fracaso, metaforizados en el itinerario hacia la muerte, cuya clave compositiva es la relación metonímica entre el progresivo deterioro del cuerpo del general y la incuestionable clarividencia del fracaso. En otros términos, pretende priorizar una lectura desde la dimensión política cuyo contenido sería la actualidad del fracaso de Bolívar y su utopía de la unidad latinoamericana desde nuestra actualidad de crisis endémica. Es decir, lectura de la utopía revolucionaria desde la antiutopía reaccionaria.
\end{abstract}

\title{
Historia y novela
}

El mismo García Márquez confirma en la nota final que titula Gratitudes su rigurosa voluntad de recuperación histórica. "Durante dos años largos me fui hundiendo en las arenas movedizas de una documentación torrencial, contradictoria y muchas veces incierta... " aunque esta voluntad no implica necesariamente el afán testimonial, puesto que nuestro autor es conciente de la función simbólica y trascendente de la literatura frente a la limitada y módica de la crónica. Por ello, afirma en la misma nota que "[...] los fundamentos históricos me preocupaban poco, pues el último viaje por el río es el tiempo menos documentado de la vida de Bolivar." Es decir, esta voluntad de recuperación histórica que parece ser el eje de la obra, se halla presidida por una clara conciencia literaria, dado que la mirada sobre los hechos y las acciones de los personajes se realiza desde el enfoque analógico, simbólico y metaforizante de la literatura. En este cruce simbiótico de perspectivas, los hechos históricos se enriquecen con la plurivalencia y la multiplicidad sugerente de las claves novelescas. Dice el autor en Gratitudes:

este libro no habria sido posible sin el auxilio de quienes trillaron esos territorios antes que yo, durante un siglo y medio, y me hicieron más fácil la temeridad literaria de contar una vida con una documentación tiránica, sin renunciar a los fueros desaforados de la novela.

Tomando como horizonte de reflexión las claves emergentes del marco teórico esbozado en la introducción, seffalaremos someramente algunos elementos desglosados de la novela, cuyo análisis revela la esencia posmoderna de su composición:

El laberinto. Es la imagen que representa la situación compleja del libertador, conformada por la concurrencia de varios factores negativos, fatalmente sin salida, como su estado de salud, sin esperanzas de recuperación, su precaria situación política, prácticamente marginado de la conducción del estado, la frustrada campaña para unificar la Gran Colombia y su nulidad para el amor. En la última página de la novela, después de suministrárseles los santos óleos, al general 
lo estremeció la revelación deslumbrante de que la loca carrera entre sus males y sus sueños llegaba en aquel instante a la meta final. El resto eran las tinieblas. Carajo, suspiró ¡Cómo voy a salir de este laberinto! (269)

Imagen del libertador. En la frase inicial de la novela, que reproducimos al comenzar estos comentarios, se presenta la corporeidad decadente, esperpéntica y carnavalizada del general. Los accesos de tos, las fiebres, los vómitos y los dolores múltiples desnudan las miserias de un cuerpo estragado y enfermo, rumbo a la aniquilación y la muerte. "José Palacios no descuidó un instante al general, que habia delirado de fiebre en la hamaca desde el atardecer" (145). La secuencia hilvanada por el proceso de decadencia de su cuerpo, y en general de su salud, se entreteje con los episodios que agravan la fatalidad del laberinto: "La noche en que se enteró de la muerte de Sucre, el general sufrió un vómito de sangre" (192). Cuando emprende la última campanfa para recuperar Venezuela, perdida de antemano, su cuerpo no resiste el mal tiempo y las miasmas malignas de las ciénagas,

el general se quejó de dolores en el bazo y el higado, y José Palacios le preparó una pócima del manual francés, pero los dolores se hicieron más intensos y la fiebre aumentó. Al amanecer estaba en tal estado de postración que lo llevaron sin sentido a la villa de Soledad. (214)

La linealidad de las acciones deja escaso margen para el suspenso y las sorpresas. Sin embargo, García Márquez logra crear un suspenso dramático con el artificio de las intermitentes mejorias del general que logran aplazar su muerte y mantienen la expectativa del desenlace, a pesar del conocimiento que de la historia obviamente tiene el lector. La última mejoria, que sobreviene cuando ya parecía irrecuperable, representa la clásica reacción del cuerpo antes de la muerte, que le permite a nuestro autor mostrar a Bolívar en su último intento de contemplar lúcidamente la muerte de sus sueños.

Al mediodia, alentado por la música, se tomó una taza de caldo y comió masas de sagú y pollo hervido... Con estos ojos no muero. La esperanza casi perdida de que el doctor Révérend hiciera un milagro volvió a renacer en todos. (266)

Pero la muerte llega finalmente, y en uno de los mejores momentos de la novela. Se presenta más bien como en un escenario teatral, entre cuyos espectadores está el mismo general:

Examinó el aposento con la clarividencia de sus vísperas, y por primera vez vio la verdad: la última cama prestada, el tocador de lástima cuyo turbio espejo de paciencia no lo volvería a repetir, el aguamanil de porcelana descarchada con el agua y la toalla y el jabón para otras manos, la prisa sin corazón del reloj octogonal desbocado hacia la cita ineluctable del 17 de diciembre a la una y siete minutos de su tarde final... (269)

Anticipo de la muerte. Desde las primeras líneas la novela juega con la idea de la muerte. Esta ya está presente en el cuerbo y en los sueños del libertador, y en consecuencia la travesía por el 
río Magdalena obedece más al impulso de la inercia que a la voluntad implícita en las acciones humanas programadas en función de objetivos y metas. En la imagen de la primera página ("...pero el estado de éxtasis en que yacia a la deriva parecía de alguien que ya no era de este mundo") encontramos los elementos metafóricos indicadores de la presencia de la muerte que la novela revelará en su desarrollo, a través de los avances y los retrocesos inscriptos en las caídas y las mejorias repentinas e intermitentes del general, concomitantes con las evoluciones también fluctuantes de la campaña política y militar.

El clima dramático, vagamente evanescente y expectante de esta doble muerte anunciada, posibilita el entretejido de imágenes y figuras que instauran la dimensión mágica y sorprendente propia del discurso novelesco de García Márquez. Suefios, delirios, pesadillas, fantasmas y leyendas transitan profusamente por la escritura neutralizando la presión de la crónica y evidenciando la intencionalidad de contar la muerte desde sus múltiples costados y manifestaciones. A intervalos cada vez más breves, el general sufría "[...] crisis de demencia, aunque al amanecer... se metería en las aguas yertas de la bañera tratando de restaurar las fuerzas estragadas por el horror de las pesadillas" (18) Cuando sale cabalgando de Bogotá, una mujer le dice al pasar "Ve con Dios, fantasma", luego saluda de lejos a Manuela Saenz, su fiel amante, a quien nunca más podrá ver. En Mompox el libertador delira después de un diluvio, en una clara alegoría del naufragio de América,

José Palacios... lo oyó hablar con la buena dicción y el timbre nítido de la juventud, que para entonces sólo recobraba en sueños. Habló de Caracas, una ciudad en ruinas que ya no era la suya, con las paredes cubiertas de papeles de injurias contra él, y las calles desbordadas por un torrente de mierda humana. (116).

Los fantasmas del fracaso y la cercana muerte acosan al general y lo sepultan en un laberinto del que logra fugarse sólo a medias, a través de la pesadilla y el delirio: "Prosiguió con un salterio de lamentos amargos, residuos de una gloria desbaratada que el viento de la muerte se llevaba en piltrafas." (117) Es en esta dirección mágica donde los signos de la realidad se convierten en símbolos.

Historicidad. Hemos mencionado antes la confesión de García Márquez acerca de la consulta de una profusa documentación para conocer el contexto histórico en que se desenvuelve el relato. No obstante, la historia, o mejor la historiografia, no interesa en la novela en su carácter de dato o crónica a ser reproducida fielmente, sino interesa como soporte contextual de los sucesos narrados y como horizonte de interpretación de las proyecciones significativas que esos hechos pueden albergar cuando se los traspone a las claves simbólicas del discurso literario. En otras palabras, lo histórico, por una parte, oficia en esta novela de componente ficcional, de materia prima con la que el autor construye la "otra historia", es decir la fábula novelesca, y por otra, organiza la textura de la trama con la ingeniosidad sugerente del artista genial que abandona en la construcción novelesca indicios de múltiples lecturas y de diversos niveles de comprensión de los hechos. Como la mayoría de las nuevas novelas históricas latinoamericanas, El general en su laberinto tal como propone nuestro análisis, intenta la recuperación histórica desde una visión de la actualidad americana. 
Hay en la novela otros tópicos significativos como los amores del general (o su rescate por la memoria y el ensueño), el latiguillo del supuesto viaje a Inglaterra y el valor actancial de sus siete acompañantes, entre quienes se destaca nítidamente su mayordomo de toda la vida, José Palacios, un civil que en la vida real se desbarrancó anímicamente tras la muerte de Bolívar, se abandonó al alcohol y murió de cirrosis y alterado mentalmente ya muy anciano.

Epilogo. El análisis de El general en su laberinto que se propone en este breve trabajo intenta un acercamiento al texto a partir de la intersección entre historia y ficción, sustentada en una tesis básica: la obra de García Márquez es una novela no un libro de historia. Por ello, independientemente del personaje y de los acontecimientos en los que se halla involucrado, la obra lleva implícita una lectura de la historia de América Latina desde la crisis de la actualidad, sustentada en los parámetros desestructurantes y en cierto modo desesperanzados del contexto de la llamada Posmodernidad.

Otras obras anteriores a la comentada se edifican sobre los últimos días del libertador. Es el caso de Las cenizas del libertador (1987) del escritor venezolano Fernando Cruz Kronfly que envuelve a Bolívar en una trama inventada y en una nebulosa que pretende crear suspenso artificialmente. El autor eslabona artificiosamente misterios absurdos como la parte clausurada del barco, que al final resulta un episodio banal e intrascendente, algo asi como una trivial reminiscencia de Los premios de Cortázar.

También el colombiano Alvaro Mutis publicó en 1978 un cuento largo titulado El último rostro, presunto fragmento de una novela sobre los últimos días del libertador que nunca apareciós. 